\title{
METHODS OF FUEL MINERAL FUNDS AND COMBINED AGRICULTURAL ACTIVITIES
}

\author{
M.KH.Mamadaliev-T.F.N. Associate Professor \\ M.SH.Holdarov, Assistant \\ Andijan branch of Tashkent State Agrarian University
}

http://doi.org/10.35410/IJAEB.2019.4463

\begin{abstract}
Annotation. In the article, when a combined aggregate with minimal tillage is applied to the soil, at one passage in the field, the underground soil is softened and fertilized in two layers to the softened place in the lentasimon method and the opportunity to obtain a feather on the softened, fertilized road is created.
\end{abstract}

Keywords: Aggregate, softener, push, spreader, fertilizer conductor, fertilizing bunker, tractor, base wheel.

\section{INTRODUCTION}

Fertilizers are a key factor in the recovery and enhancement of soil fertility. Science and best practices have shown that the effective use of mineral fertilizers can increase crop yields by up to $60 \%$.

Fertilizers play an important role in improving soil fertility. However, chemical or local fertilizers do not provide the same benefits under different soil conditions. For example, groundwater is supposed to provide up to $25 \%$ of the annual amount of nitrogen fertilizer in the grassy soils during the development period before the sowing.

When nitrogen is administered in large quantities, the plant becomes sick, pollutes groundwater, and soil fertility decreases. Therefore, in the future, establishing fertilizer card insertion rates will not only save cotton, but also reduce the cost of fertilizer losses by $50 \%$. will also cause it to remain.

In developed countries, farming is cultivated every 5-7 years. Although a few centners of harvest are lost when sown on a slightly loosened soil without plowing, the economics of energy use have been calculated to be more profitable than lost cotton.

The influence of fertilizer on the development of germination roots and the norm varies depending on the root system, location and timing. Therefore, the local fertilizer method shows a number of specific requirements. The local fertilizer efficiency determines the location of the fertilizer in the soil (fertilizer in the ribbon, its width, depth, germination range). 
In particular, a highly concentrated fertilizer band cannot be placed in contact with or near the seed. Also, it is not allowed to place the main fertilizer in the planting sequence as it affects the germination of the young and affects the productivity.

The best results are achieved by placing the main fertilizer in a deeper layer than the processed seed. Previous studies have shown that increasing the dose of primary and primary fertilizer under cultivated crops is more efficient than twisting the seed line rather than a single strand.

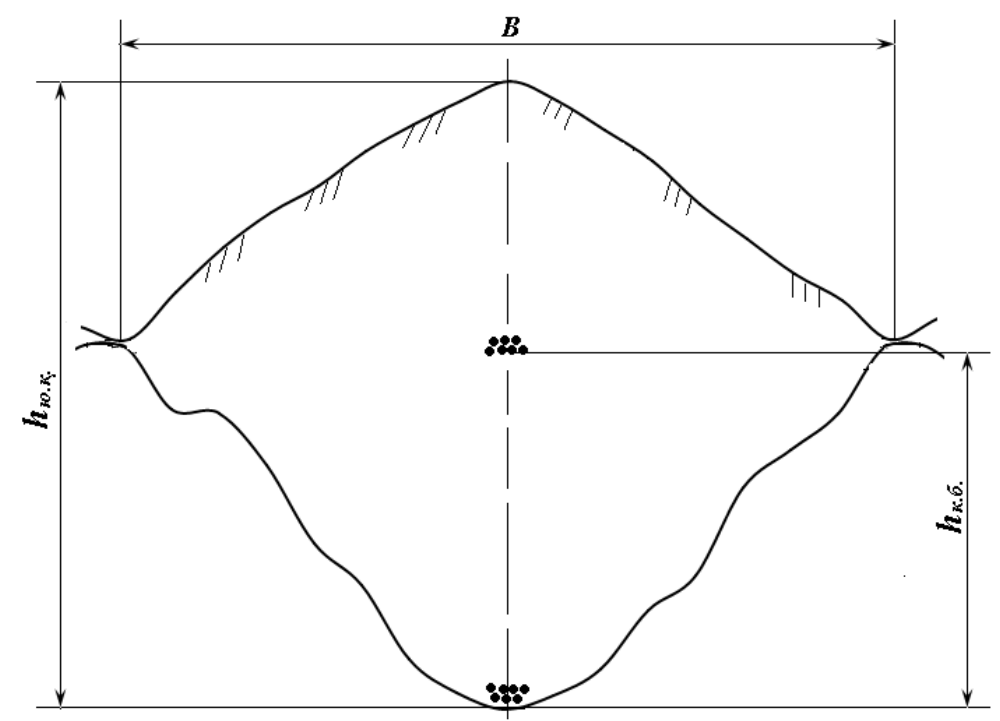

Hyu.q. - The thickness of the softened layer; Width of B-formed pus; hb - the height of the upper layer relative to the lower layer Figure 1.

Upper layer laying height relative to the lower layer of fertilizers

The analysis shows that the most effective way of fertilizing fertilizers should be in two layers of ribbon, ie, $30.40 \mathrm{~cm}$, and the pre-sowing scale at a depth of $20 \ldots 25 \mathrm{~cm}$.

To implement this method, it is advisable to tape the tape over the softened and softened soil at a single passage of the unit and push it onto the softened, fertilized path (Figure 1).

Based on the analysis of the literature and the results of the research, the technology of minimum soil tillage in cotton cultivation and its combined aggregate was developed. According to the proposed technology, cotton-free fields will not be plowed in the fall, but will only be softened and fertilized by last season's irrigation furrows, and new spikes for sowing next year in these softened and fertilized areas. is formed.

Soil-based technology for minimum tillage, as mentioned above, was carried out in the autumn, when the cotton-harvested cotton stalks were removed at a depth of $30-40 \mathrm{~cm}$ at one passage of 
the furrows. The softened area is softened in two layers with softened bottoms and tape-like at a height of 30-40 cm, and the old fluffs are applied to these softened and fertilized areas and the height is $25-30 . \mathrm{cm}$ hairs are formed, that is, under the furrows of the previous season, furrows are softened and fertilized, and furrows are replaced by flanks (Figure 2).

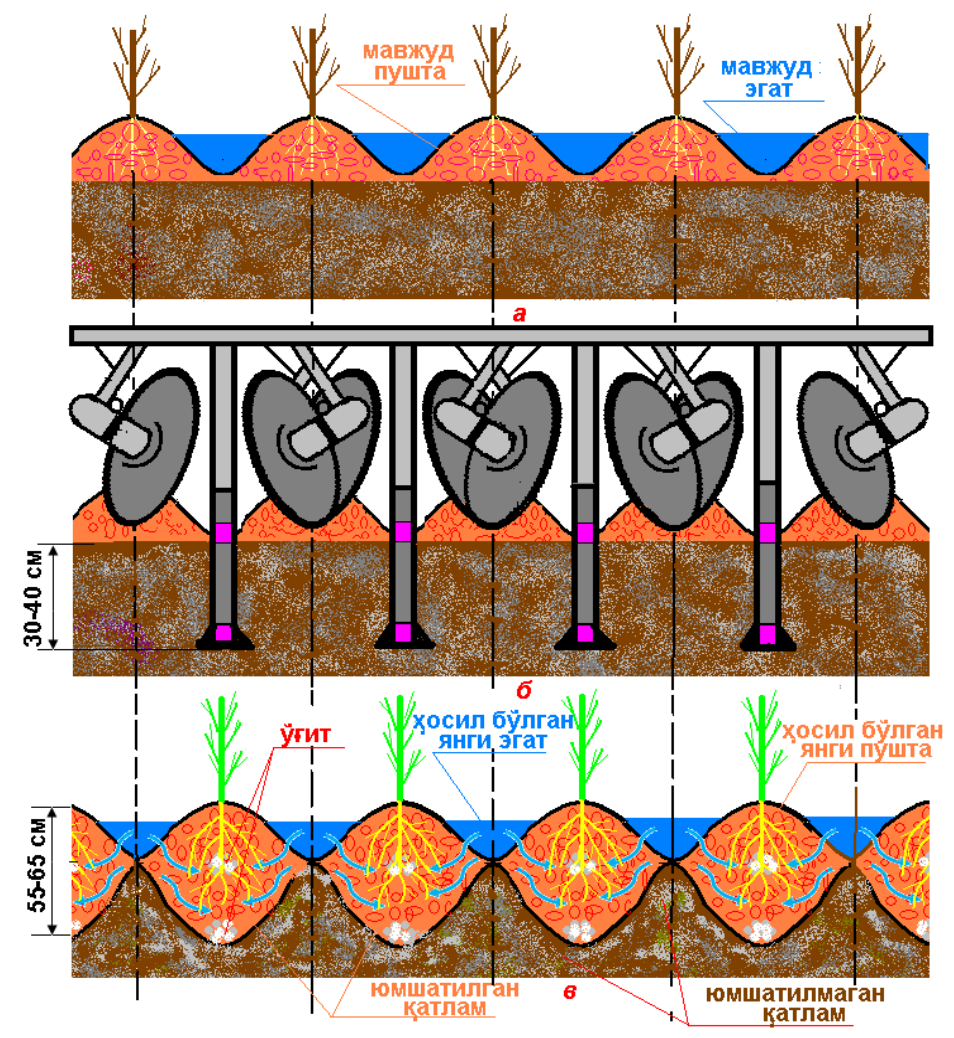

A- existing humps and furrows prior to aggregation; $\beta$-aggregate workflow; v-formed new blush and furrow.

Figure 2. Minimum tillage technology and schemes for combined process unit implementation

\section{CONCLUSION}

According to the analysis, an effective method of fertilizer application is to put two layers of tape in the bottom layer, ie the bottom of the softened layer and above it $30 \mathrm{~cm}$. It has been shown that it is desirable to tape the tape on the softened and softened soil under a single passage of the aggregate to produce such a method and to create a pile on the softened, fertilized path.

An analysis of the literature shows that fertilizing and plowing the land to reduce the cost of fuel and other costs for the preparation of fields for sowing, as well as the harmful effects of agricultural machinery on soil has shown that it is possible to use a combined aggregate that performs the straightening, boring, grinding, and blasting operations of a single unit. 


\section{REFERENCES}

1. AN Khudoyorov, M. Yuldasheva, U. Abdumalikov Technological process of combined aggregate fertilizer. Scientific-practical conference on "Effective use of advanced agricultural technologies in the cultivation, storage and processing of agricultural products, development of irrigation and reclamation systems: problems and solutions". Collection of lectures. - Tashkent, 2015 - B. 254-255

2. AN Khudoyorov, MA Yuldasheva, M.Sh.Holdarov. Improved technology for fertilizing the softened layer. Problems of enhancing the efficiency of energy and resource efficiency of modern production ". Andijan 2018.

3. Khudoyorov A., Mamadaliev M. Theoreticheskoye oblique parameters of rihlitlya combinirovannogo aggregate // Technique in selskom Hozyaystve.-Moscow, 2009.

4. Hudoyorov AN, Mamadalaev MH, Mirzaev Kh.A. Combined aggregate with minimal tillage // Scientific and technical journal of Fergana Polytechnic Institute. - 2006. - №4-B. 59-61. 